\title{
High Coercivity and High Saturation Magnetization Mn-Al Thin Films
}

\author{
J. H. Huang, P. C. Kuo and S. C. Shen
}

\begin{abstract}
Mn-Al thin films with the composition of 31-68 at.\% $\mathrm{Mn}$ were prepared by $\mathrm{rf}$ magnetron sputtering at various substrate temperature then annealing in vacuum. Effects of the chemical composition, substrate temperature and annealing temperature on the magnetic properties of $\mathrm{Mn}-\mathrm{Al}$ films have been investigated. The analysis of $x$-ray diffraction and magnetic measurement indicate that $\tau$-phase was synthesized at a composition range of 40-60 at.\% Mn. However, the formation of large amount of $\tau$-phase occurred at $\mathrm{Mn}_{50}-\mathrm{Al}_{50}$ films, which have a high coercivity up to about $3000 \mathrm{Oe}$ and a fairly large saturation magnetization of about $420 \mathrm{emu} / \mathrm{cc}$.
\end{abstract}

\section{INTRODUCTION}

$\mathrm{T}$ $\mathrm{HE}$ existence of a ferromagnetic phase in the $\mathrm{Mn}-\mathrm{Al}$ system containing about $45 \sim 58$ at. \% $\mathrm{Mn}$ is a result of the metastable $\tau$-phase, the structure and magnetic properties of which have been extensively investigated [1]-[7]. This ferromagnetic $\tau$-phase has a tetragonal $\mathrm{L} 1_{0}$ type superstructure and high crystalline anisotropy energy as large as about $10^{7} \mathrm{erg} / \mathrm{cc}$. The ferromagnetism of the $\tau$-phase occurs because the magnetic moments of Mn atoms in $0,0,0$ sites are parallel to one another. The disorder in the $\tau$-phase structure may cause the $\mathrm{Mn}$ atoms move into $1 / 2,1 / 2,1 / 2$ sites, and the $\mathrm{Mn}$ atoms in 0,0 , 0 and $1 / 2,1 / 2,1 / 2$ sites are coupled antiferromagnetically [2]. Many mechanisms have been proposed for the $\tau$-phase formation $[8,9]$. The usually accepted mechanism is that the high-temperature non-magnetic $\epsilon$-phase (hcp) transforms into a non-magnetic $\epsilon^{\prime}$-phase (orthorhombic) by an ordering reaction, then transforms into a metastable ferromagnetic $\tau$-phase (fct) by a martensitic mode.

Metal thin films have been developed for recording media to cope with the ever-increasing demand of high density recording. Among them, Co-based alloy films have come into practical use. Preparation of $\tau$-phase in $\mathrm{Mn}-\mathrm{Al}$ films and their magnetic properties have been investigated by Morisako and Matsumoto [10]. According to their reports, ferromagnetic $\tau$-phase of $\mathrm{Mn}$-Al binary alloy films were synthesized at $\mathrm{Mn}$ content of about 60 at. \% and substrate temperature of about $150^{\circ} \mathrm{C}$. However, since these films exhibited low saturation magnetization Ms of about $120 \mathrm{emu} / \mathrm{cc}$, which is only one-fourth of the bulk mate-

Manuscript received July 3, 1994; revised October 24, 1994. This work was supported by the National Science Council of Taiwan, Republic of China, under the grant NSC-83-0405-E002-002.

The authors are with the Institute of Materials Science and Engineering, National Taiwan University, Taiwan.

IEEE Log Number 9411680 rial, they were not applicable for the magnetic recording media. Further investigations were studied by doping the elements such as, $\mathrm{Cu}, \mathrm{Ni}, \mathrm{Fe}, \mathrm{Co}, \mathrm{Ag}, \mathrm{Zn}[11]-[14]$; they found a maximum saturation magnetization of about 300 $\mathrm{emu} / \mathrm{cc}$ for a $\mathrm{Mn}_{38}-\mathrm{Al}_{40}-\mathrm{Cu}_{22}$ film. However, the coercivity decreased to about $220 \mathrm{Oe}$. These films were composed of both the $\mathrm{Mn}-\mathrm{Al} \tau$-phase and $\mathrm{Mn}$-Al-Cu $\kappa$-phase. The single ferromagnetic $\tau$-phase has not been fabricated before.

In this paper, we report the effects of the chemical composition, substrate temperature and annealing temperature on the magnetic properties and formation of ferromagnetic $\tau$-phase of $\mathrm{Mn}$-Al films. A nearly single phase of ferromagnetic $\tau$-phase with good magnetic properties was produced in this study.

\section{EXPERIMENTAL}

The films have been deposited by means of an rf magnetron sputtering system. A mosaic target consisting of a high purity aluminium disk $(99.999 \%)$ overlaid with small high purity manganese pieces $(99.99 \%)$. This arrangement provides a wide range of effective target compositions and therefore films compositions. Films were deposited on glass substrates at substrate temperature Ts ranging from 30 to $250^{\circ} \mathrm{C}$

Applied rf power source was working at $80 \mathrm{~W}$ and a typical deposition rate was $0.5 \mathrm{~nm} / \mathrm{s}$. The base pressure in the system was $5 \times 10^{-7}$ Torr, and after the high purity Ar gas was introduced, the sputtering pressure was set at $1 \mathrm{mTorr}$. Films in thickness of $0.8 \mu \mathrm{m}$ were used in this study. Thermal annealing was carried out at temperature range between 350 and $550^{\circ} \mathrm{C}$ in vacuum.

Crystal structures of the deposited films were characterized by $\mathrm{x}$-ray diffractometer (XRD) and their compositions were determined by electron probe microanalyzer (EPMA) calibrated by a standard of $\mathrm{Mn}_{55}-\mathrm{Al}_{45}$ alloy. Magnetic properties of the films were measured with vibrating sample magnetometer (VSM) at room temperature in the maximum applied field of $10 \mathrm{kOe}$.

\section{Results AND Discussion}

The Mn-Al films with Mn concentrations ranging from 31 to 68 at. \% were produced, their magnetic properties were measured to examine the existence of the $\tau$-phase. The films were deposited at substrate temperature (Ts) of $30^{\circ} \mathrm{C}$ and then annealed at $410^{\circ} \mathrm{C}$ for $30 \mathrm{~min}$. Fig. 1 shows 


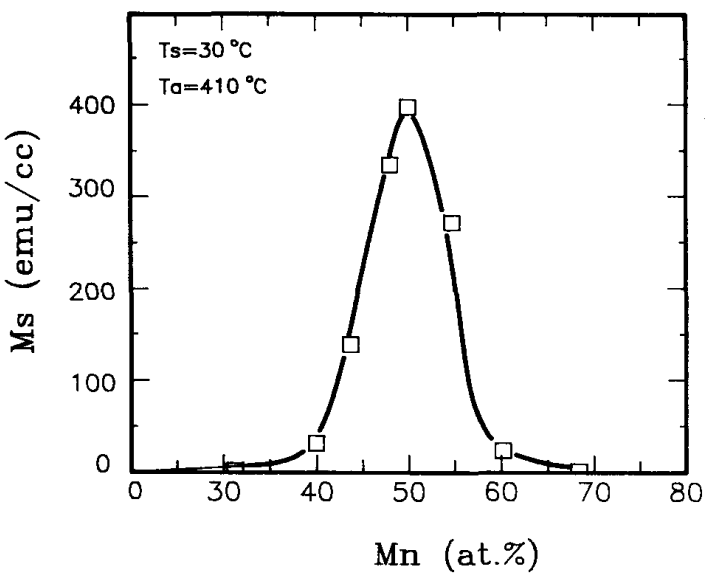

Fig. 1. Variation of saturation magnetization Ms with Mn content.

the relation between Ms and Mn content of these films. The ferromagnetic phase appeared at composition range between 40 to 60 at. \%, and the maximum Ms about 400 emu/cc was obtained for the $\mathrm{Mn}_{50}-\mathrm{Al}_{50}$ films, which was close to that of the $\tau$-phase in bulk $\mathrm{Mn}$-Al alloys [2]. This indicated that the film was almost completely transformed into $\tau$-phase. Fig. 2 shows the relation between the coercivity $\mathrm{Hc}$ and the $\mathrm{Mn}$ content of the films, the Hc of the $\mathrm{Mn}_{50}-\mathrm{Al}_{50}$ film was about $3000 \mathrm{Oe}$, which is much larger than that of the bulk Mn-Al alloys (about 500 1000 Oe) [2].

Fig. 3 shows the substrate temperature dependence of Ms for the $\mathrm{Mn}_{50}-\mathrm{Al}_{50}$ films. The as-deposited samples were non-magnetic phase for $\mathrm{Ts}$ below $100^{\circ} \mathrm{C}$, above which a low Ms value were detected. This indicated that only a small amount of $\tau$-phase formed in the as-deposited films. After annealing these films at $410^{\circ} \mathrm{C}$, the $\mathrm{Ms}$ increased for all the samples, especially for the films deposited at low Ts. Thus, the $\epsilon \rightarrow \tau$ phase transformation was occurred during the annealing treatment. However, since the Ms of the annealed films decreased with increasing $T s$, the transformation fraction should decrease with increasing $T s$. The results of $x$-ray diffraction measurements for the samples of $\mathrm{Mn}_{50}-\mathrm{Al}_{50}$ films deposited at different substrate temperature are shown in Fig. 4. The intensity of the $\epsilon$-phase peaks increased with decreasing substrate temperature and the half-width of the peaks $B$ decreased with decreasing substrate temperature. This indicates that the films deposited at lower Ts have a large and more perfect crystalline structure than the films deposited at higher Ts. Since the $c$ plane of the hexagonal structure in the $\epsilon$-phase and the (111) plane of the tetragonal structure in the $\tau$-phase have the same spacing distance [3], the results of $x$-ray diffraction could not identify which phase was formed. Because the $\epsilon$-phase and $\tau$-phase are antiferromagnetic and ferromagnetic, respectively, the results of the Ms measurement (Fig. 3) can confirm that all the as-deposited films are mostly composed of the $\epsilon$-phase.

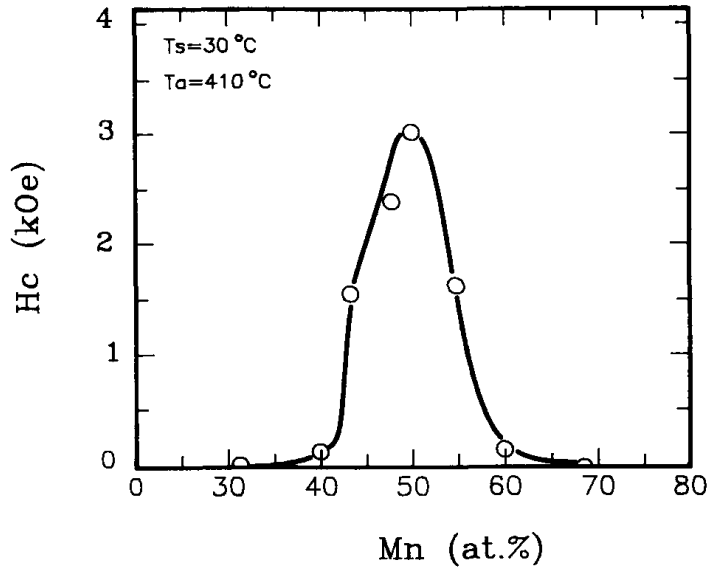

Fig. 2. Variation of coercivity $\mathrm{He}$ with $\mathrm{Mn}$ content.

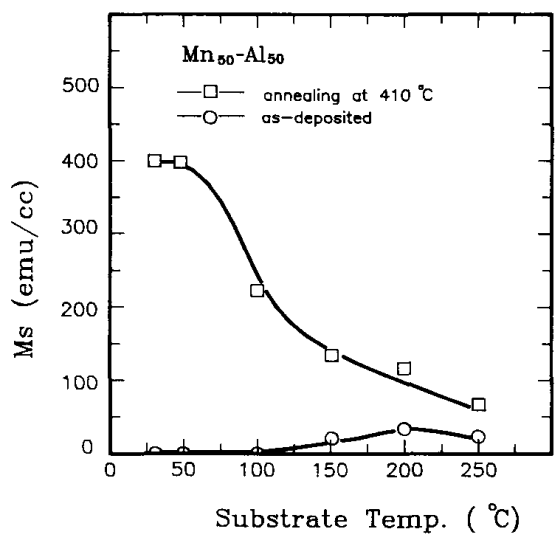

Fig. 3. Saturation magnetization $\mathrm{Ms}$ of $\mathrm{Mn}_{50}-\mathrm{Al}_{50}$ films as a function of substrate temperature. The annealing time is $30 \mathrm{~min}$

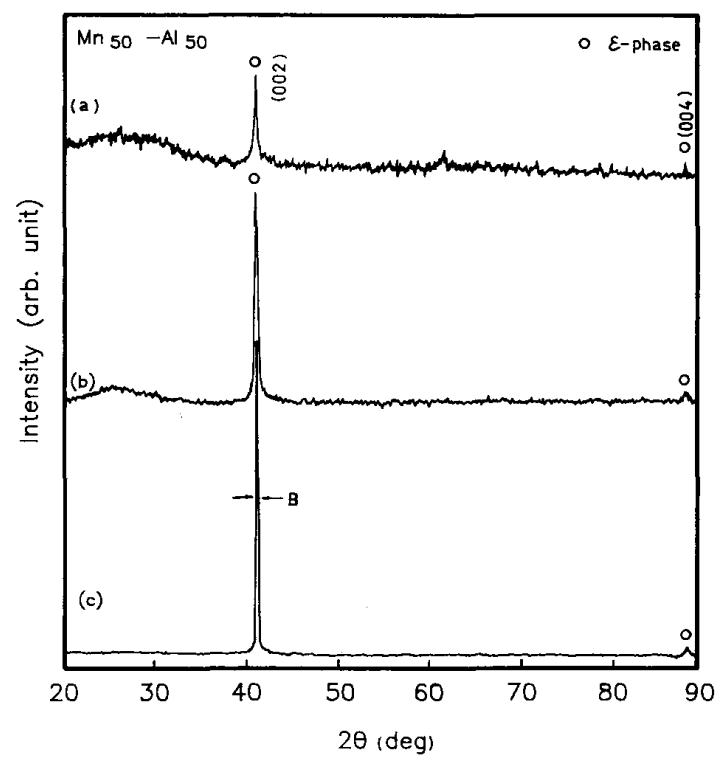

Fig. 4. X-ray diffraction patterns of the as-deposited $\mathrm{Mn}_{50}-\mathrm{Al}_{50}$ films with substrate temperature: (a) $200^{\circ} \mathrm{C}$; (b) $100^{\circ} \mathrm{C}$; (c) $30^{\circ} \mathrm{C}$. 


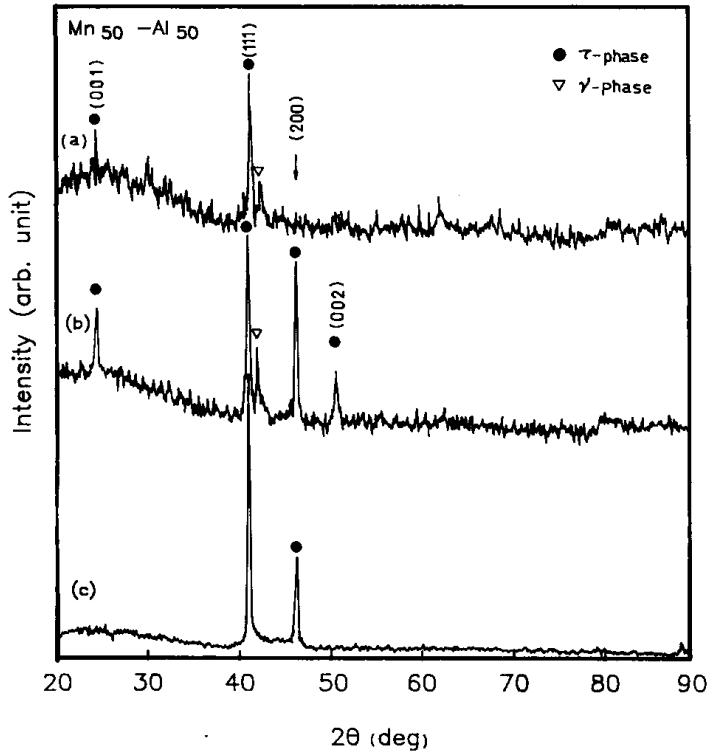

Fig. 5. X-ray diffraction patterns of the corresponding samples in Fig. 4 after annealing at $410^{\circ} \mathrm{C}$ for $30 \mathrm{~min}$.

The above results indicate that at low substrate temperature the sputtered atoms arrived on the substrate should not have enough energy to form the metastable $\tau$-phase or the equilibrium $\beta$ and $\gamma$-phase, and the $\epsilon$-phases were formed due to the super quenching effect.

After annealing at $410^{\circ} \mathrm{C}$ for $30 \mathrm{~min}$., the $\epsilon$-phases transfer into $\tau$-phases, their $\mathrm{x}$-ray diffraction patterns are shown in Fig. 5. The annealed samples with Ts above $100^{\circ} \mathrm{C}$ were composed of $\gamma$-phase and $\tau$-phase while the films deposited at $\mathrm{Ts}$ of $30^{\circ} \mathrm{C}$ were composed of pure $\tau$-phases. These results were consistent with the Ms measurement of Fig. 3 which shows that the Ms of annealed films has a maximum value at Ts of $30^{\circ} \mathrm{C}$ and decreased with increasing Ts. The decrease of $\mathrm{Ms}$ is due to that the nonmagnetic $\gamma$-phase appeared after the annealing treatment.

In Fig. 5, the diffraction peak of $(001)$ plane $(d=$ $3.54 \AA$ ) of the $\tau$-phase was clearly seen in the patterns(a) and (b). It is larger than that of the powder $\mathrm{x}$-ray diffractometry of $\tau$-phase [3], suggesting a preferential orientation of the (001) plane of the $\tau$-phase parallel to the film plane for the two samples. Hence the c axis, which is the easy axis of the $\tau$-phase, is perpendicular to the film plane; this effect was not clear on the M-H loop due to the poor magnetic properties of these films. On the contrary, the films deposited at low Ts of $30^{\circ} \mathrm{C}$ have a (111) plane of $\tau$-phase crystallites oriented parallel to the film plane. This indicates that the $\mathrm{c}$ axis of the $\tau$-phase is incline to the film surface at angle about $37.9^{\circ}$ [12].

Fig. 6 shows $\mathrm{M}-\mathrm{H}$ curves of $\mathrm{Mn}_{50}-\mathrm{Al}_{50}$ films with $\mathrm{Ts}$ $=30^{\circ} \mathrm{C}$, the applied fields were in both directions parallel and normal to the film plane. The $\mathrm{M}-\mathrm{H}$ curves show that the film exhibits almost isotropic characteristics. This consistent with the result of the X-ray diffraction (Fig. 5,

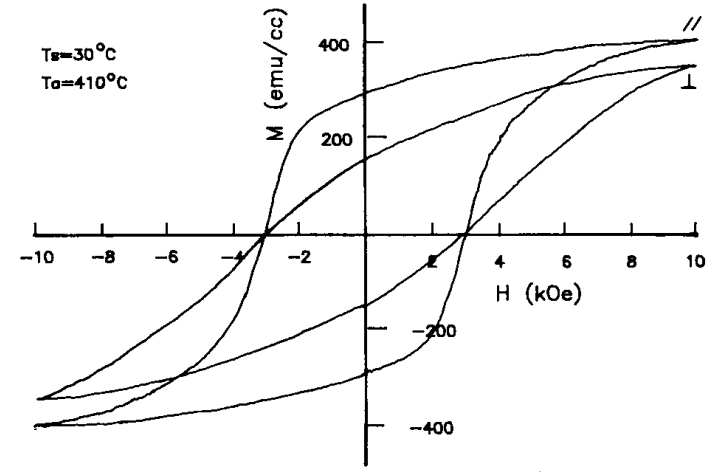

Fig. 6. Magnetization curves for $\mathrm{Mn}_{50}-\mathrm{Al}_{50}$ films with substrate temperature of $30^{\circ} \mathrm{C}$. The annealing time is $30 \mathrm{~min}$.

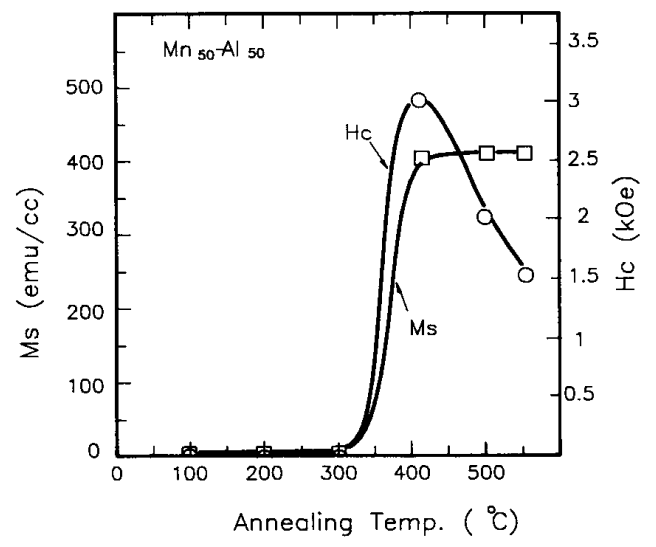

Fig. 7. Annealing temperature dependence on $\mathrm{Ms}$ and $\mathrm{Hc}$ for $\mathbf{M n}_{50}-\mathrm{Al}_{50}$ films. The annealing time is $30 \mathrm{~min}$.

pattern (c)) which shows that the (111) plane of $\tau$-phase crystallites parallel to the film plane and the easy crystal axis of the $\tau$-phase incline to the film surface at angle about $37.9^{\circ}$.

Different annealing temperatures were performed for the Mn-Al films. Fig. 7 shows the magnetic properties of the $\mathrm{Mn}_{50}-\mathrm{Al}_{50}$ film as a function of annealing temperature between 100 and $550^{\circ} \mathrm{C}$. It is seen that the $\mathrm{Ms}=0$ at annealing temperature below $300^{\circ} \mathrm{C}$ above which the Ms increased rapidly with increasing annealing temperature and at $500^{\circ} \mathrm{C}$, the $\mathrm{Ms}$ reached its maximum value and remained unchanged with the temperature. This means that the transformation of $\epsilon$ to $\tau$-phase was complete at temperature above $500^{\circ} \mathrm{C}$. The $\mathrm{Hc}$ decreases with increasing annealing temperature at temperature above $410^{\circ} \mathrm{C}$. This may be due to the grain growth at high temperature annealing. However, the exact mechanism is not clear at present. Further research is underway, and will be reported later. The effect of annealing time on the magnetic properties of the $\mathrm{Mn}_{50}-\mathrm{Al}_{50}$ films was shown in Fig. 8. The Ms was increased rapidly at annealing time above 3 minutes. At the annealing time of about 100 minutes, Ms reached its maximum value of about $420 \mathrm{emu} / \mathrm{cc}$ and did not drop even at the annealing time up to 3.5 hours. 


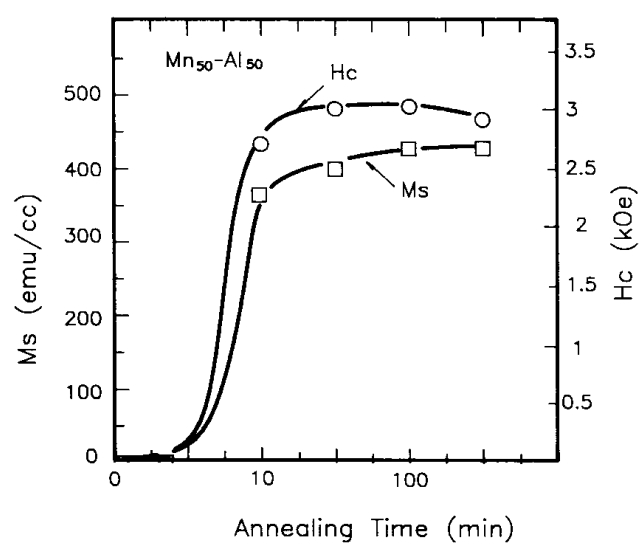

Fig. 8. Annealing time dependence on $\mathrm{Ms}$ and $\mathrm{Hc}$ for $\mathrm{Mn}_{50}-\mathrm{Al}_{50}$ films. The annealing temperature is $410^{\circ} \mathrm{C}$.

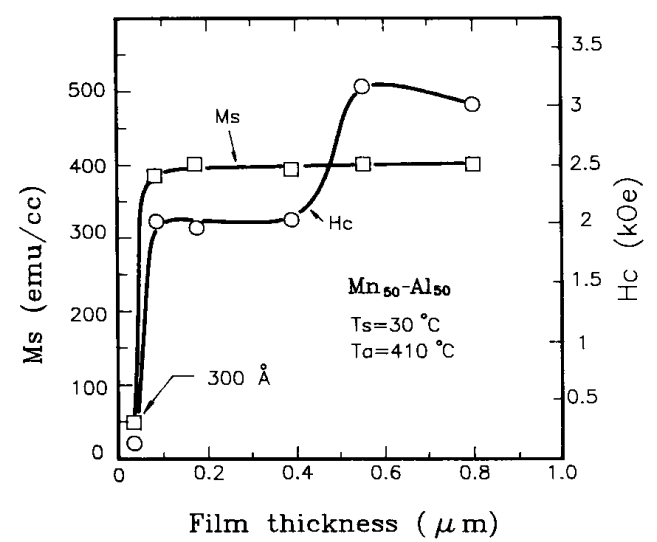

Fig. 9. Thickness dependence on $\mathrm{Ms}$ and $\mathrm{Hc}$ for $\mathrm{Mn}_{50}-\mathrm{Al}_{50}$ films. The annealing time is $30 \mathrm{~min}$.

From the above results, it is found that the $\mathrm{Mn}_{50}-\mathrm{Al}_{50}$ films have a very high thermal stability. This is in contrast to the work of Morisako et al. [14], who found that the $\tau$-phase in the $\mathrm{Mn}_{60}-\mathrm{Al}_{40}$ and $\mathrm{Mn}_{57}-\mathrm{Al}_{40}-\mathrm{Ni}_{3}$ decomposed into equilibrium phase and $\mathrm{Ms}$ decrease rapidly at temperature above $400^{\circ} \mathrm{C}$. The $\tau$-phase of our $\mathrm{Mn}_{50}-\mathrm{Al}_{50}$ films were stable even elevating the annealing temperature up to $550^{\circ} \mathrm{C}$.

Fig. 9 shows the thickness dependence of $\mathrm{Mn}_{50}-\mathrm{Al}_{50}$ films on the magnetic properties. For the decrease of film thickness to about $1000 \AA$, the Ms decreased slightly with decreasing film thickness. Below $700 \AA$, the Ms decreased rapidly to about $50 \mathrm{emu} / \mathrm{cc}$ for the $300 \AA$ film. Since the formation of the ferromagnetic $\tau$-phase is a shear transformation [9], the transformation occurred by cooperative atomic movements. Atoms in the interface region between the substrate and the $\mathrm{Mn}-\mathrm{Al}$ film were hardly expected to take place during the shear transformation because the movements of these atoms were restricted by the rigid substrates. This effect may hamper the $\epsilon \rightarrow \tau$ transformation especially in the ultra thin film and leads to the sharp decrease of Ms.
The Hc of the films with thickness between $700 \AA$ and $0.4 \mu \mathrm{m}$ was about $1900 \mathrm{Oe}$, and it increased to a maximum value of about $3200 \mathrm{Oe}$ at film thickness of $0.58 \mu \mathrm{m}$. The coercivity of these $\mathrm{Mn}-\mathrm{Al}$ films was large than that of the bulk Mn-Al alloys $(500 \sim 1000 \mathrm{Oe})$. This is due to that the magnetoelastic energy arises from the rather high stress between substrates and $\mathrm{Mn}-\mathrm{Al}$ films during the shear transformation. The internal stresses in the $\mathrm{Mn}-\mathrm{Al}$ films presumably have a maximum value at the film thickness of about $0.58 \mu \mathrm{m}$.

\section{Conclusion}

We have studied the sputtered thin films of the Mn-Al system over a wide composition range and for various substrate temperatures. A ferromagnetic $\tau$-phase of $\mathrm{Mn}_{50^{-}}$ $\mathrm{Al}_{50}$ films with high $\mathrm{Ms}$ and $\mathrm{Hc}$ have been produced, they have a high coercivity up to about 3000 Oe and a large saturation magnetization of about $420 \mathrm{emu} / \mathrm{cc}$.

The films deposited at low substrate temperature $\left(30^{\circ} \mathrm{C}\right)$ were composed of $\epsilon$-phase with well crystallite structure, and they will transfer into $\tau$-phases after annealing at temperature about $410^{\circ} \mathrm{C}$. Increasing the substrate temperature will decrease the crystallite size of the as-deposited film, and the nucleation of equilibrium $\gamma$-phase occur red as well. Thus, a single $\tau$-phase cannot be obtained by further annealing treatment.

\section{ACKNOWLEDGMENT}

This work was supported by the National Science Council of Taiwan under grant NSC-83-0405-E002-002.

\section{REFERENCES}

[1] H. Kono, "On the ferromagnetic phase in manganese-aluminium," J. Phys. Soc., Japan, vol. 13, p. 1444, 1958.

[2] A. J. J. Koch, P. Hokkeling, M. G. V. D. Sterg, and K. J. DeVos, "New material for permanent magnets on a base of $\mathrm{Mn}$ and $\mathrm{Al}$, , $J$. Appl. Phys., vol. 31, p. 75S, 1960.

[3] B. Braun and J. A. Goodkoop, "On x-ray and neutron diffraction investigation of the magnetic phase in Mn-Al alloy," Acta Cryst., vol. 16 , p. 737,1963

[4] J. J. Van Den Broek, H. Donkersloot, G. Van Tendeloo, and J. Van Landuyt, "Phase transformation in pure and carbon-doped $\mathrm{Mn}-\mathrm{Al}$ alloys," Acta Metallu., vol. 27, p. 1497, 1979.

[5] J. Van Landuyt, G. Van Tendeloo, J, J. Van Den Broek, and H. Donkersloot, "Permanent magnetism and microstructure in MnAl(C)," J. Mag. Mag. Mater., vol. 15, no. 8, p. 1451, 1980.

[6] M. A. Bohlmann, J. C. Koo, and J. H. Wise, "Mn-Al-C for permanent magnets," J. Appl. Phys., vol. 52, p. 2542, 1981.

[7] C. T. Lee, K. H. Han, I. H. Kooh, and W. K. Choo, "Phase and lattice parameter relationships in rapid solidified and head-treated $\mathrm{Mn}$ Al-C pseudo-binary alloys,"' J. Mater. Res., vol. 7, no. 7, p. 1690, 1992.

[8] Ye. Z. Vintaykin, V. A. Udovenko, I. S. Belyatskaya, N. N. Luarsabishvili, and S. Yu. Makushev, "Formation of a ferromagnetic phase in manganese-aluminium alloys," Fiz. metal. metalloved, vol. 38, p. 398,1974

[9] S. Kohima, T. Ohtani, N. Kato, K. Kojima, Y. Sakamoto, I. Konno, M. Tsukahara, and T. Kubo, "Crystal transformation and orientation of Mn-Al-C magnetic alloys," AIP Conf. Proc., vol. 24, p. 768, 1974.

[10] A. Morisako and M. Matsumoto, "Synthesis of ferromagnetic $\tau$-phase of Mn-Al films by sputtering," J. Appl. Phys., vol. 61, no. 8, p. $4281,1987$. 
[11] J. X. Shen, Roger D. Kirby, and D. J. Sellmyer, "The structure and magneto-optic properties of Mn-Al based thin films," J. Appl. Phys., vol. 67 , no. 9 , p. $4929,1990$.

[12] A. Morisako, M. Matsumoto, and M. Naoe, "Sputtered Mn-Al-Cu films for magnetic recording media," IEEE Trans. Magn., vol. 23, no. 5, p. $2470,1987$.

[13] A. Morisako, N. Kohshiro, and M. Matsumoto, "Crystal structure and magnetic properties of $\mathrm{Mn}-\mathrm{Al}-\mathrm{Ni}$ films prepared by sputtering," J. Appl. Phys., vol. 67, no. 9, p. 5655, 1990.

[14] M. Matsumoto, A. Morisako, and J. Ohshima, "Properties of ferromagnetic $\mathrm{Mn}-\mathrm{Al}$ thin films with additives," J. Appl. Phys., vol. 69 , no. 8 , p. 5172,1991 .

J. H. Huang was born in Hualien, Taiwan, on March 29, 1957. He received the M.Sc. degree in 1988 and the Ph.D. degree in 1993, both in materials science and engineering from the National Taiwan University, Taiwan.

He is now a postdoctoral researcher in the Institute of Materials Science and Engineering, National Taiwan University, Taiwan.
P. C. Kuo was born in Taichug, Taiwan, on October 28,1948 . He received the B.Sc. and M.Sc. degree in physics in 1972 and 1974, respectively, and the Ph.D. degree in Electrical Engineering in 1985 from National Cheng Kung University, Taiwan.

Since 1986, he has been a professor at the Institute of Materials Science and Engineering, National Taiwan University, Taiwan.

S. C. Shen was born in Hsin-Ying, Taiwan, on March 11, 1963. He received the diploma degree in metallurgy in 1985 from National Taipei Institute of Technology, Taiwan.

He worked for Feng-Hsin steel company, Ltd. between 1991 and 1993. $\mathrm{He}$ is now a graduate student in the Institute of Materials Science and Engineering, National Taiwan University, Taiwan. 